\title{
Prevalência de anticorpos anti-Toxoplasma gondii em bovinos abatidos em matadouros do estado da Bahia, Brasil
}

\author{
Prevalence of antibodies anti-Toxoplasma gondii in slaughtered \\ cattle at stockyards in the State of Bahia, Brazil \\ Fernando H. Spagnol'1; Elisson B. Paranhos²; Laura Lucia dos S. Oliveira²; \\ Simoni M. de Medeiros ${ }^{3}$; Carlos Wilson G. Lopes ${ }^{4}$; George R. Albuquerque ${ }^{5 *}$
}

\begin{abstract}
${ }^{1}$ Programa de Pós-Graduação em Ciência Animal, Universidade Estadual de Santa Cruz - UESC e Bolsista FAPESB
${ }^{2}$ Graduação em Medicina Veterinária, Departamento de Ciências Agrárias e Ambientais, Universidade Estadual de Santa Cruz - UESC e Bolsista IC - PIBIC (CNPq / UESC)

${ }^{3}$ Curso de Enfermagem, Centro Universitário UNIABEU

${ }^{4}$ Departamento de Parasitologia Animal, Instituto de Veterinária, Universidade Federal Rural do Rio de Janeiro - UFRRJ e Bolsista CNPq

${ }^{5}$ Departamento de Ciências Agrárias e Ambientais, Universidade Estadual de Santa Cruz - UESC
\end{abstract}

Recebido em 31 de Maio de 2008

Aceito em 27 de Fevereiro de 2009

\section{Resumo}

Foram analisados 600 soros de bovinos abatidos nos matadouros sob Inspeção Municipal de Ilhéus e Itabuna, e no matadouro frigorífico sob Inspeção Federal em Jequié, BA, para anticorpos anti-Toxoplasma gondii por imunofluorescência indireta. A prevalência total foi de 11,83\% (71), sendo os animais positivos 19,3\% (37) no matadouro de Ilhéus, 9,8\% em Itabuna (21) e 6,8\% (13) em Jequié. Dos animais positivos, 65 (91,5\%) tiveram título de 1:64, e 6 (8,5\%) de 1:256. A maioria dos soros positivos para T. gondii foram oriundos de animais provenientes de granjas leiteiras e foram abatidos nos matadouros sob inspeção municipal em comparação com aqueles animais que procederam de fazendas com criação extensiva, e abatidos em matadouros sob inspeção federal.

Palavras-chave: Toxoplasmose, prevalência, gado de abate.

\begin{abstract}
Serum samples of 600 slaughtered cattle from Ilhéus and Itabuna Municipal slaughterhouse and Jequié Federal slaughterhouse, all of them located in the State of Bahia were screened using an indirect immunofluorescent antibody test against Toxoplasma gondii. Prevalence was $11.83 \%$ (71), and positive samples were distributed as 19.3\% (37) from Ilhéus, 9.8\% (21) from Itabuna and 6.8\% (13) from Jequié slaughterhouses respectively. From positive cattle, 91.5\% (65) had titles $1: 64$, and $8.5 \%$ (6) had title 1:256. The majority of serum positive samples against T. gondii were related to animals from dairy farms which were slaughtered at municipality stockyards under municipal inspection in comparison with those slaughtered at Federal inspection which were related to beef cattle that were raised in farms extensively.
\end{abstract}

Keywords: Toxoplasmosis, prevalence, slaughtered cattle.

\section{Introdução}

Toxoplasmose é uma parasitose cosmopolita, sendo as condiçóes do meio ambiente determinantes do grau da distribuiçáo do parasito. A infecção é mais prevalente em climas quentes que em frios e regiôes de montanhas, e mais em regiôes úmidas do que em áreas secas. Isso, provavelmente, devido às condiçôes favoráveis à esporulaçấo e sobrevivência dos oocistos no meio ambiente (DUBEY;

\footnotetext{
*Autor para correspondência: George R. Albuquerque

Departamento de Ciências Agrárias e Ambientais,

Universidade Estadual de Santa Cruz - UESC, BA 415 km 16, CEP 45.662-000

Salobrinho, Ilhéus - BA, Brasil; e-mail: gralbu@uesc.br
}

BEATTIE, 1988). Outro fator importante são os hábitos culturais e alimentares de uma população, cujo consumo de carne crua ou mal cozida é considerado um dos principais fatores de risco para a população humana (TENTER et al., 2000).

A infecção pelo $T$. gondii em adultos saudáveis é normalmente assintomática, porém, a doença pode ser severa em indivíduos imunodeprimidos, como portadores da Síndrome da Imunodeficiência Adquirida (SIDA) e transplantados (TENTER et al., 2000; DUBEY, 2004). Em mulheres que têm o primeiro contato com o parasita durante a gravidez, há grande possibilidade de transmissão 
transplacentária, que poderá acarretar desde perda gradativa de visão nos casos mais leves, até fetos mal formados, morte pré-natal e aborto, em graves infecçóes (DUBEY, 2004).

Bovinos são mais resistentes à toxoplasmose, mas, quando presente, os sintomas clínicos mais comuns são: febre, inapetência, diarréia, dispnéia, descargas nasais e tosse (SANGER et al., 1953; COSTA et al., 1977; DUBEY, 1983; OLIVEIRA et al., 2001) e aborto (CANADA et al., 2002).

Toxoplasma gondii foi isolado, pela primeira vez, em tecidos bovinos por Sanger et al. (1953), quando identificaram a presença de formas do parasito. Desde então, T. gondii vem sendo isolado de diversos órgáos (ZARDI et al., 1964; CATAR et al., 1969; MUNDAY, 1978; DUBEY, 1983; DUBEY; THULLIEZ, 1993). No Brasil, Jamra et al. (1969), Spósito Filha et al. (1988) isolaram T. gondii de tecidos de bovinos.

Dubey (1983), em trabalho experimental com bezerros e vacas prenhes, concluiu que $T$. gondii pode permanecer viável nos tecidos dos bovinos até a idade de abate desses animais.

Objetivou-se com o presente trabalho verificar a prevalência de anticorpos anti-T. gondii em bovinos abatidos nos matadouros sob Inspeção Municipal, dos municípios de Itabuna e Ilhéus, e sob Inspeção Federal no de Jequié, estado da Bahia, Brasil.

\section{Material e Métodos}

Foram utilizadas amostras de sangue de 600 bovinos, sendo 192 e 214 provenientes dos matadouros sob Inspeção Municipal dos municípios de Ilhéus e Itabuna, respectivamente, e 194 do matadouro frigorífico sob Inspeção Federal no município de Jequié, independentemente de raça e idade, identificados de acordo com o sexo e município de procedência.

O cálculo, para a obtenção de um número representativo dos animais, foi realizado com auxílio do programa Epi Info, versão 6.04 (CDC, Atlanta) (DEAN; ARNER, 2002). Os três matadouros juntos abatem cerca de 130.000 bovinos por ano. A amostragem dos animais foi calculada pela média dos resultados encontrados nos trabalhos de Passos et al. (1984), Marana et al. (1994) e Daguer et al. (2004), com uma prevalência esperada de $27,50 \%$ e o pior resultado aceitável de $23,20 \%$.

As coletas foram efetuadas durante o período de outubro de 2004 a setembro de 2005 , sendo o sangue adquirido por ocasião da sangria, em tubos de ensaio de $15 \mathrm{~mL}$ sem anticoagulante. Terminada a coleta, os tubos foram acondicionados em caixas isotérmicas com gelo reciclável e levados ao Laboratório de Parasitologia Veterinária da Universidade Estadual de Santa Cruz, onde foram centrifugados a $350 \mathrm{~g}$, por 10 minutos, para uma melhor separação do soro, e este acondicionado em criotubos de 2,0 mL em duplicata, identificados e armazenados a uma temperatura de $-20{ }^{\circ} \mathrm{C}$. Os soros foram levados para o Laboratório de Coccídios e Coccídioses Projeto Sanidade Animal (Embrapa/UFRRJ), devidamente acondicionados em caixas isotérmicas, para realização da sorologia.

Para a pesquisa de anticorpos anti-T. gondii nas vacas foi utilizado o teste de Imunofluorecência Indireta (IFI), segundo Camargo (1964). Para isso, foram utilizadas lâminas apropriadas para IFI, contendo antígenos da cepa C do T. gondii, soros controles positivos e negativos e soro antibovino conjugado com isotiocianato de fluoresceína (F-7887 ${ }_{\text {TM }}$, Sigma-Chemical, EUA). A diluição inicial foi de 1:16,em diluiçôes sequenciais na base quatro até a negativação, sendo considerados positivos títulos $>64$ (COSTA et al., 1977).

O teste do Qui-quadrado foi utilizado para comparar a soropositividade dos animais em relaçáo ao sexo, local do matadouro e sistema de inspeção.

\section{Resultados e Discussáo}

Das 600 amostras de soros bovinos analisadas, obteve-se uma prevalência de $11,83 \%$ (71) pela IFI. Após a análise individual por município, observou-se 19,1\% (37) de prevalência em Ilhéus, 9,8\% (21) em Itabuna e 6,7\% (13) em Jequié (Tabela. 1).

A literatura consultada mostra grande discrepância nos valores de resultados dos estudos soroepidemiológicos para T. gondii em bovinos, no Brasil, variando de 1,03 a 48,51\% (GONDIM et al., 1999; MARANA et al., 1995). Analisando os estudos realizados exclusivamente em matadouros, tiveram a positividade pela IFI variando entre 9,0 e 41,4\% (PASSOS et al., 1984; DAGUER et al., 2004).

A prevalência encontrada neste estudo está abaixo das encontradas por Marana et al. (1994) e Daguer et al. (2004), que encontraram, respectivamente, 32,34 e 41,4\% de soropositividade em bovinos abatidos na região de Londrina e Pato Branco, no Paraná. Porém é mais elevada que a de Passos et al. (1984) e Meireles et al. (2003), que encontraram 9,0 e 11,0\% de positividade, em Belo Horizonte, MG, e Taquarituba, SP.

O único estudo soroepidemiológico para anticorpos anti-T. gondii em bovinos, na Bahia, foi realizado por Gondim et al. (1999), que analisaram o soro de 194 bovinos oriundos de rebanhos da Caatinga e Recôncavo, pelo Teste de Aglutinação em Látex (LAT), encontrando 1,03\% de positividade. Esse resultado apresenta valores bem abaixo dos encontrados nos bovinos abatidos nos matadouros dos municípios de Ilhéus, Itabuna e Jequié.

Dos 71 animais positivos na IFI, 65 (91,5\%) tiveram títulos sorológicos de 1:64, e $6(8,5 \%)$ com 1:256. Esses resultados são semelhantes aos de trabalhos que relacionam a titulação de anticorpos anti-T. gondii, mostrando que a positividade, normalmente, é maior na diluição de 1:64, com poucos títulos de 1:256 (GARRIDO et al., 1972; COSTA; COSTA, 1978; MARANA et al., 1994; OGAWA et al., 2005; ALBUQUERQUE et al., 2005), sendo que Garrido et al. (1972) afirmaram que animais com títulos mais baixos possuem infecção latente e, com títulos mais elevados, possuem uma forma ativa da doença.

Não houve também diferenças significativas quanto ao sexo ( $\mathrm{p}=0,71$ ), corroborando com Arias et al. (1994) e Daguer et al. (2004). Houve diferenças significativas quanto ao sistema de inspeção Municipal e Federal $(\mathrm{p}=0,01)$ e quanto aos matadouros $(\mathrm{p}=0,0004)$ (Tabelas 2 e 3$)$. Tal fato pode estar associado às condiçóes de criação dos animais abatidos nos matadouros municipais, principalmente no de Ilhéus, onde se observa um maior número de bovinos de descarte com maior presença de fêmeas, oriundas de granjas leiteiras. Albuquerque (2004), ao trabalhar com bovinos leiteiros na bacia leiteira Sul Fluminense, RJ, 
Tabela 1. Distribuição de anticorpos anti-Toxoplasma gondii em bovinos abatidos nos matadouros municipais de Ilhéus e Itabuna e no do frigorífico de Jequié, BA.

\begin{tabular}{ccccccc}
\hline \multirow{2}{*}{ Local } & \multicolumn{2}{c}{ Título de anticorpos } & & \multicolumn{2}{c}{ Sexo } \\
\cline { 2 - 3 } & $\mathbf{6 4}$ & $\mathbf{2 5 6}$ & Total de positivos (\%) & Macho (\%) & Fêmea (\%) \\
\hline Ilhéus $(\mathrm{n}=192)$ & 33 & 4 & $37(19,3 \%)$ & & $6(19,4 \%)$ & $31(19,3 \%)$ \\
Itabuna $(\mathrm{n}=214)$ & 19 & 2 & $21(9,8 \%)$ & & $9(16,7 \%)$ & $12(7,5 \%)$ \\
Jequié $(\mathrm{n}=194)$ & 13 & 0 & $13(6,8 \%)$ & & $11(7,3 \%)$ & $2(4,7 \%)$ \\
Total $(\mathrm{n}=600)$ & 65 & 6 & & $71(11,83 \%)$ & $26(11,0 \%)$ & $45(12,3 \%)$ \\
\hline
\end{tabular}

Tabela 2. Associação entre bovinos sororreagentes ao IFI para IgG anti-Toxoplasma gondii e o sistema de inspeção em animais abatidos nos matadouros municipais de Ilhéus e Itabuna e no do frigorífico de Jequié, BA.

\begin{tabular}{|c|c|c|c|c|c|c|}
\hline \multirow{2}{*}{ Serviço de inspeção } & \multicolumn{2}{|c|}{ Animais } & \multirow{2}{*}{$\chi^{2}$} & \multirow{2}{*}{ Valor de $p$} & \multirow{2}{*}{$\begin{array}{c}\text { Chances de } \\
\text { ocorrer (OR) }\end{array}$} & \multirow{2}{*}{$\begin{array}{c}\text { Intervalo de } \\
\text { confiança } 95 \%\end{array}$} \\
\hline & Positivos & Negativos & & & & \\
\hline Municipal & 58 & 348 & \multirow{2}{*}{6,53} & \multirow{2}{*}{0,01} & \multirow{2}{*}{2,32} & \multirow{2}{*}{$1,2-4,58$} \\
\hline Federal & 13 & 181 & & & & \\
\hline
\end{tabular}

Tabela 3. Associação entre bovinos sororreagentes ao IFI para IgG anti-Toxoplasma gondii e os matadouros municipais de Ilhéus e Itabuna e no do frigorífico de Jequié, BA.

\begin{tabular}{|c|c|c|c|c|c|c|}
\hline \multirow{2}{*}{$\begin{array}{c}\text { Município do } \\
\text { matadouro }\end{array}$} & \multicolumn{2}{|c|}{ Animais } & \multirow{2}{*}{$\chi^{2}$} & \multirow{2}{*}{ Valor de $p$} & \multirow{2}{*}{$\begin{array}{c}\text { Chances de ocorrer } \\
\text { (OR) }\end{array}$} & \multirow{2}{*}{$\begin{array}{c}\text { Intervalo de Confiança } \\
95 \%\end{array}$} \\
\hline & Positivos & Negativos & & & & \\
\hline Ilhéus & 37 & 155 & \multirow{2}{*}{6,64} & \multirow{2}{*}{0,009} & \multirow{2}{*}{2,19} & \multirow{2}{*}{$1,19-4,06$} \\
\hline Itabuna & 21 & 193 & & & & \\
\hline Ilhéus & 37 & 155 & \multirow{2}{*}{12,43} & \multirow{2}{*}{0,0004} & \multirow{2}{*}{3,32} & \multirow{2}{*}{$1,64-6,85$} \\
\hline Jequié & 13 & 181 & & & & \\
\hline Itabuna & 21 & 193 & \multirow{2}{*}{0,91} & \multirow{2}{*}{0,33} & \multirow{2}{*}{1,51} & \multirow{2}{*}{$0,73-3,11$} \\
\hline Jequié & 13 & 181 & & & & \\
\hline
\end{tabular}

enfatizou que a bovinocultura intensiva ou semi-intensiva sempre foi mais propícia à infecção por $T$. gondii. Razáo essa de grande importância, quando se usa carne resfriada oriunda do abate de vacas de descarte para consumo da população local, onde a permanência de cistos viáveis em animais soro reagentes facilitaria a dispersão de $T$. gondii.

\section{Agradecimentos}

Ao PROCAD/CAPES e FAPESB e aos Médicos Veterinários Aloísio Correia Leite, Francisco Salles Almeida Filho e Pedro Alexandre Gomes Leite, inspetores, lotados nos respectivos matadouros.

\section{Referências}

ALBUQUERQUE, G. R. Fatores de risco associados ao Toxoplasma gondii em rebanhos bovinos da bacia leiteira da microrregiáo do Vale do Paraíba Fluminense, estado do Rio de Janeiro. 2004. 76 f. Tese (Doutorado em Ciências Veterinárias) - Universidade Federal Rural do Rio de Janeiro, Seropédica.
ALBUQUERQUE, G. R. et al. Prevalência de anticorpos anti-Toxoplasma gondii em bovinos leiteiros do vale do Paraíba Sul Fluminense, estado do Rio de Janeiro. Revista Brasileira de Parasitologia Veterinária, v. 14, n. 3, p. 125-128, 2005.

ARIAS, L. M. et al. Seroepidemiology of Toxoplasma gondii (Apicomplexa) in meat producing animals in Costa Rica. Revista de Biologia Tropical, v. 42, n. $1-2$, p. $15-20,1994$.

CAMARGO, M. E. Improved technique of indirect immunofluorescence for serological diagnosis of toxoplasmosis. Revista do Instituto de Medicina Tropical de Sáo Paulo, v. 6, n. 3, p. 117-118, 1964.

CANADA, N. et al. Isolation of viable Toxoplasma gondii from naturally infected aborted bovine fetuses. Journal of Parasitology, v. 88, n. 6, p. $1247-1248,2002$

CATAR, G.; BERGENDI, L.; HOLKOVA, R. Isolation of Toxoplasma gondii from swine and cattle. The Journal of Parasitology, v. 55, n. 5, p. 952-955, 1969.

COSTA, A. J. et al. Experimental infection of bovines with oocysts of Toxoplasma gondii. Journal of Parasitology, v. 63, n. 2, p. 212-218, 1977. 
COSTA, A. J.; COSTA, E. P. Frequência de bovinos reagentes à imunofluorescência indireta para Toxoplasma gondii em Poços de Caldas, MG, Brasil. Arquivos da Escola de Veterinária da UFMG, v. 30, n. 1, p. 47-51, 1978.

DAGUER, H. et al. Soroprevalência de antocorpos anti-Toxoplasma gondii em bovinos e funcionários de matadouros da microrregiáo de Pato Branco, Paraná, Brasil. Ciência Rural, v. 34, n. 4, p. 1133-1137, 2004.

DEAN, A. G.; ARNER, T. Epi Info: Epidemiology of program office. Disponível em: <http://www.cdc.gov/epiinfo/index.html>. Acesso em: 20 de Abril de 2002.

DUBEY, J. P. Distribuition of cysts and tachyzoites in calves and preagnant cows inoculated with Toxoplasma gondii oocysts. Veterinary Parasitology, v. 13, n. 3, p. 99-211, 1983.

DUBEY, J. P. Toxoplasmosis: a waterborne zoonosis. Veterinary Parasitology, v. 126, n. 1-2, p. 57-72, 2004.

DUBEY, J. P.; BEATTIE, C. P. Toxoplasmosis of animals and man. Boca Raton: CRC Press, 1988. 75 p.

GARRIDO, J. A. et al. Estudios sobre la epidemiologia de la toxoplasmosis: la infeccion entre los animales de consumo, encuestas serologicas en Madrid, mediante la reaccion de inmunofluorescencia. Medicina Tropical, v. 48, p. 11-23, 1972.

GONDIM, L. F. P. et al. Serological survey of antibodies to Toxoplasma gondii in goats, sheep, cattle and water buffaloes in Bahia State, Brazil. Veterinary Parasitology, v. 82, n. 4, p. 273-276, 1999.

MARANA, E. R. M. et al. Ocorrência de anticorpos anti-Toxoplasma gondii em bovinos de corte, abatidos em matadouros do norte do Paraná- Brasil. Semina: Ciências Agrárias, v. 15, n. 1, p. 38-40, 1994.

MARANA, E. R. M. et al. Ocorrência de anticorpos anti-Toxoplasma gondii em bovinos de leite, do norte do Paraná- Brasil. Semina: Ciências Agrárias, v. 16, n. 1, p. 40-42, 1995.
MEIRELES, L. R.; GALISTEO Jr., A. J.; ANDRADE Jr., H. F. Serological survey of antibodies to Toxoplasma gondii in food animals from São Paulo state, Brazil. Brazilian Journal of Veterinary Research and Animal Scince, v. 40, n. 4, p. 267-271, 2003.

MUNDAY, B. L. Bovine toxoplasmosis: experimental infections. International Journal for Parasitology, v. 8, p. 285-288, 1978.

OGAWA, L. et al. Occurrence of antibodies to Neospora caninum and Toxoplasma gondii in dairy cattle from the northern region of the Paraná State, Brazil. Arquivos Brasileiros de Medicina Veterinária e Zootecnia, v. 57, n. 3, p. 312-316, 2005.

PASSOS, L. M. F.; LIMA, J. D.; FIGUEIREDO, B. L. Determinação da infecção por Toxoplasma gondii em bovinos abatidos em Belo Horizonte (MG) através da frequência de anticorpos e tentativa de isolamento a partir de musculatura diafragmática. Arquivos Brasileiros de Medicina Veterinária e Zootecnia, v. 36, n. 5, p. 581-589, 1984.

SANGER, V. L. et al. Toxoplasmosis. V. Isolation of Toxoplasma from cattle. Journal of the American Veterinary Medical Association, v. 123, n. 917, p. 87-91, 1953.

SPÓSITO FILHA, E. et al. Toxoplasma gondii em bovinos: evidenciação do parasita a partir de retina e diafragma de animais abatidos em matadouros do Estado de São Paulo, Brasil. Arquivos do Instituto Biológico, v. 55, n. 1-4, p. 43-47, 1988.

TENTER, A. M.; HECKEROTH, A. R., WEISS, L. M. Toxoplasma gondii: from animals to humans. International Journal for Parasitology, v. 30, p. 1217-1258, 2000.

ZARDI, O. et al. Studi epidemiologici sulla toxoplasmosi: Isolamento di stipiti di Toxoplasma gondii da animali domestici. Nuovi Annali D’Igieni e Microbiologia, v. 15, n. 6, p. 546-551, 1964. 